\title{
A sociedade aberta de intérpretes da Constituição: limites e possibilidades de aplicação à realidade constitucional brasileira ${ }^{1}$
}

\author{
Flávio Elias Riche ${ }^{2}$ \\ Natália Braga Ferreira ${ }^{3}$
}

\begin{abstract}
Resumo: No pensamento contemporâneo, a hermenêutica desempenha um papel central para a Teoria da Constituição. Tal entendimento, contudo, comporta uma pluralidade de perspectivas teóricas. O presente trabalho restringe-se à análise do pensamento de Peter Häberle, em razão de sua influência notória não apenas no constitucionalismo português e espanhol, mas também no brasileiro, sendo, neste caso, inclusive aplicado em decisões recentes do Supremo Tribunal Federal. Espera-se, assim, a partir do estudo do que se tem tornado um dos principais marcos teóricos do constitucionalismo pátrio, contribuir para uma compreensão mais aprofundada de sua própria realidade jurídico-social.
\end{abstract}

Palavras-chave: Tópica. Hermenêutica constitucional. Sociedade aberta de intérpretes da Constituição.

\begin{abstract}
In contemporary thought, hermeneutics plays a central role for the Constitutional Theory. This understanding, however, includes a plurality of theoretical perspectives. The present work is restricted to the analysis of Peter Häberle's thought, because of its influence not only in the notorious Portuguese and Spanish Constitutionalism, but also in Brazil, in which case, also applied to recent decisions of the Supreme Court. It is expected therefore, from the study of what has become a major theoretical framework of Constitutionalism homeland, to contribute to a deeper understanding of their own legal and social reality.
\end{abstract}

Keywords: Topical. Constitutional hermeneutics. Open society of interpreters of the Constitution.

1 O texto resultou de pesquisas efetuadas no âmbito do Grupo de Pesquisa Direito e Democracia, do Instituto Brasiliense de Direito Público (IDP) entre os anos de 2008 e 2009.

2 Doutorando em Relações Internacionais pela Universidade de Brasília (UnB). Mestre em Ciências Jurídicas pela PUC-RIO. Bacharel em Ciências Sociais pela UERJ. Bacharel em Direito pela UNI-RIO. Coordenador do grupo de pesquisa Peter Häberle, do Instituto Brasiliense de Direito Público (IDP). Diplomata de carreira. E-mail: flavio.riche@ itamarati.gov.br

3 Especialista em Direito, Estado e Constituição pela UNIPLAC. Pesquisadora do Grupo de Peter Häberle, do Instituto Brasiliense de Direito Público (IDP). Assistente da Defensoria Pública da União no Distrito Federal. Advogada. E-mail: nataliabraga@yahoo.com.br 


\section{Introdução}

Os métodos hermenêuticos surgidos mais recentemente na Alemanha resultaram de uma crise da legalidade, de um estado de descontentamento e inconformismo que se estabeleceu em relação ao positivismo lógico-formal. Buscou-se, por conseguinte, desenvolver uma teoria material da Constituição, cujo fundamento, a princípio, procede da metodologia científico-espiritual de Rudolf Smend. Não obstante o caráter precursor da obra deste grande juspublicista - um intento de superação da análise meramente formalista que até então se desenvolvia na República de Weimar -, é à tópica de Theodor Viehweg que devemos atribuir a introdução das principais questões do debate alemão contemporâneo. Seja na teoria concretizadora de Konrad Hesse, seja na metódica estruturante de Friedrich Müller, ou na democratização do processo interpretativo proposta por Peter Häberle, a presença do pensamento tópico-problemático é notória. ${ }^{4}$

Dessa forma, os autores da Nova Hermenêutica convergirão em determinados aspectos, tais como: a busca de um sentido mais profundo das constituições; a negação da Lei Maior como um sistema lógicoaxiomático perfeito e acabado, tendo em vista o caráter eminentemente aberto da ordem constitucional; a revalorização da teoria material da Constituição em reação ao excesso de formalismo do positivismo clássico (contudo, sem significar um retorno à concepção de Lassalle, visto que a importância do elemento normativo não será totalmente desprezada principalmente nas teorias de Müller e Hesse); o reconhecimento da mútua reciprocidade existente entre Direito e realidade, da interação dinâmica que se opera entre eles, não mais confinando a realidade social ao espaço pré-jurídico; a superação da antinomia entre o fático e o normativo, excluindo a opção unilateral por um desses termos em detrimento do outro; a não identificação das regras clássicas de interpretação com a

\footnotetext{
4 Todavia, cabe ressaltar que a tópica "pura”, enquanto primazia absoluta do problema sobre a norma, será adotada plenamente apenas por Häberle. Tanto Hesse como Müller recepcionam o pensamento de Viehweg com ressalvas, desenvolvendo uma tópica “mitigada”, onde o elemento normativo não é desprezado (o que, de modo algum, nega o fato de que esses autores se inspiram em larga escala na orientação tópica).
} 
concretização; a negação da atividade interpretativa como puramente cognitiva, voltada unicamente para a voluntas legis ou para a voluntas legislatori, de caráter meramente reprodutor; o reconhecimento de que toda concretização é uma atividade criativa e aperfeiçoadora; a valorização do problema concreto a ser resolvido, sem o qual não há interpretação; a constatação das peculiaridades que envolvem a Constituição, de modo que sua interpretação não pode ser idêntica à de uma lei ordinária, tal como queriam os positivistas. O presente estudo tem como foco principal a análise da hermenêutica constitucional proposta por Peter Häberle e suas implicações para a realidade constitucional brasileira. Antes, contudo, é preciso expor uma das principais referências em seu pensamento.

\section{A “orientação tópico-problemática” de Theodor Viehweg}

O pensamento tópico desenvolvido por Theodor Viehweg constitui um marco da Filosofia do Direito contemporânea. Primeiramente, em razão do contexto no qual emerge, tendo como principal acontecimento o fim da Segunda Guerra Mundial e os efeitos devastadores sofridos pela civilização europeia - fatores esses que contribuíram para a consequente erosão do positivismo lógico-dedutivo, baseado na concepção de razão (solipsista) instaurada a partir de René Descartes, e até então predominante.

Tal crise paradigmática irá gerar um “vazio metodológico”, visto que as barbáries impetradas pelo nazismo, dentre outros fatores, irão demonstrar claramente a impossibilidade da manutenção do modelo jurídico hegemônico, baseado em um raciocínio dedutivo puro e negador de qualquer dimensão axiológica. Por outro lado, o resgate do jusnaturalismo, propugnado por Gustav Radbruch, apesar de atender aos anseios em prol de uma justificação ética da ordem legal, não se fazia possível em razão do nível de desenvolvimento em que se encontrava o pensamento jusfilosófico. Aqui se encontra o segundo aspecto que torna a proposta deste autor tão relevante. Pois a tópica permite superar as insuficiências do paradigma positivista de modo inovador, isto é, sem se fundamentar em nenhuma teoria do Direito natural. Em última instância, Viehweg logra uma nova forma de pensar a racionalidade jurídica, 
afastada do eixo metodológico sob o qual se assentou toda a discussão do debate filosófico moderno.

Buscará, então, resgatar o pensamento tópico da Antiguidade, principalmente a partir das obras de Aristóteles e Cícero, identificando a presença da tópica na atividade dos juristas romanos, dos glosadores medievais e no direito civil moderno. Todavia, Viehweg ressalta que, a partir da Modernidade, com a emergência do raciocínio lógico-dedutivo cartesiano e da noção de sistema, a retórica será alvo do mais puro ostracismo por parte dos pensadores, sendo relegada a segundo plano por divergir dos padrões matematizantes em vigor, constituindo um risco ao status científico que se pretendia atribuir ao Direito. Exceção a esta regra foi Gian Battista Vico. Através de sua análise acerca das distinções entre os tipos de estudo antigo e moderno, identificou o ilustre filósofo o método da Antiguidade como retórico (tópico), e o novo método como crítico. Este teria como ponto de partida um primum verum - o qual nem a dúvida pode eliminar - gerando longas cadeias dedutivas, enquanto aquele teria como ponto de partida o sensus communis - que manipula o verossímil e opera a partir de uma rede de silogismos. Apesar da precisão do método crítico, Vico afirma que ele possui diversas desvantagens perda de penetração, falta de amadurecimento do juízo, empobrecimento da linguagem, dentre outras - que, não obstante, podem ser sanadas através do antigo método retórico e de seu principal componente: a tópica (VIEHWEG, 1979, p. 20-21). Vejamos, então, o pensamento tópico antigo a partir da experiência grega e romana.

A retórica constitui um dos grandes legados da cultura greco-romana, cujo desenvolvimento inicial se operou principalmente através da atividade dos sofistas. Todavia, a terminologia tópica surgirá apenas a partir de Aristóteles. Na Tópica, assim como nas Refutações Sofísticas - partes quinta e sexta do Organon aristotélico - o tema central consiste em uma questão recorrente da filosofia antiga, já tratada inclusive por Sócrates e Platão: a velha arte da disputa, tão bem dominada pelos retóricos.

Segundo Aristóteles, a tópica não pertence ao campo do apodítico, mas do dialético. O primeiro constitui o terreno da verdade no qual se opera a atividade dos filósofos. Já o segundo se expressa através do 
dialeguestai, ou seja, da disputa no campo do meramente opinativo (endoxon), associado, pois, à atividade dos sofistas. Doravante, a proposta aristotélica objetivará o desenvolvimento de um método que, partindo de proposições oriundas das opiniões, permita a formulação de raciocínios referentes a todos os problemas passíveis de serem apresentados. Isto implica, mais precisamente, na aplicação da ciência lógica, elaborada por Aristóteles, à arte da argumentação, possibilitando que, em face de um problema qualquer colocado, seja sustentado um discurso coerente para o ataque ou para a defesa - por meio de um raciocínio baseado em opiniões que parecem ser geralmente adequadas (ex endoxon), evitando, assim, as contradições. Prova desta afirmativa é a classificação aristotélica dos raciocínios de acordo com a índole das respectivas premissas, como a apodexis - raciocínio típico da filosofia -, o raciocínio dialético, o raciocínio erístico e os pseudorraciocínios.

Assim, o objeto da tópica é dado pelo raciocínio (dialético) derivado de premissas verossímeis fundadas em opiniões reconhecidas. Nesse sentido, os topoi cumprem o papel de servir como guia na obtenção de tal raciocínio diante de um problema concreto. “Topoi são, portanto, para Aristóteles, pontos de vista utilizáveis e aceitáveis em toda parte, que se empregam a favor ou contra o que é conforme a opinião aceita e que podem conduzir à verdade.” (VIEHWEG, 1979, p. 26-27). Destarte, tornase visível que a tópica em Aristóteles traz em si uma teoria da dialética como arte retórica. Embora a concepção aristotélica seja mais elaborada, será a tópica ciceroniana que prevalecerá, exercendo maior influência histórica. Enquanto Aristóteles buscava precipuamente uma formulação teórica, enfatizando as causas, Cícero concentrava seus esforços nos resultados, tomando a tópica como uma prática da argumentação. Em razão disso, Cícero não ordenará teoricamente os topoi - entendidos aqui como lugares-comuns -, mas irá agrupá-los tendo em vista o seu melhor aproveitamento prático, de forma que não haja polêmica para a qual não se possa utilizar algum topoi, mesmo que nem todos sejam aplicáveis a qualquer situação.

Viehweg define a tópica como uma techne do pensamento, orientada para o problema, entendido como “[...] toda questão que aparentemente permite mais de uma resposta e que requer necessariamente um 
entendimento preliminar, de acordo com o qual toma o aspecto de questão que há de levar a sério e para a qual há que buscar uma resposta como solução” (VIEHWEG, 1979, p. 34). Considera, assim, o problema como algo previamente dado, o ponto central em torno do qual gira o raciocínio, servindo ao mesmo tempo de sua base e seu guia - conforme já ressaltara Aristóteles.

A tópica, ou ars inveniendi (arte da invenção), é caracterizada pela diversidade de suscitações que o problema concreto é capaz instigar, podendo ser classificada em dois graus distintos, no que tange à sua organização. A tópica de primeiro grau ocorre frequentemente em nosso cotidiano, quando buscamos justificações para o nosso agir, através de uma seleção arbitrária de pontos de vista mais ou menos causais, procurando com isso obter premissas objetivamente adequadas e profundas, cujas conclusões lancem uma luz ao problema. Neste caso, os topoi são utilizados de forma isolada, razão pela qual a tópica de primeiro grau mostra-se muitas vezes insuficiente, sendo necessária a organização de um conjunto de pontos de vista preparados previamente através de um catálogo de topoi, conforme a especificidade do problema. A este procedimento se denomina tópica de segundo grau.

No que diz respeito ao aspecto qualitativo, os topoi podem ser: gerais, quando aplicáveis a qualquer tipo de problema, consistindo em generalizações muito amplas; especiais, quando aplicáveis apenas a um determinado ramo do saber ou círculo de problemas, levando à formulação de catálogos especializados de topoi. Em ambos os casos, a função é a mesma:

A função dos topoi, tanto gerais como especiais, consiste em servir a uma discussão de problemas. Segue-se daí que sua importância tem de ser muito especial naqueles círculos de problema em cuja natureza está não perder nunca o seu caráter problemático. Quando se produzem mudanças de situações e em casos particulares, é preciso encontrar novos dados para tentar resolver os problemas. Os topoi, que intervêm com caráter auxiliar, recebem por sua vez seu sentido a partir do problema. A ordenação com respeito ao problema é essencial para eles. À vista de cada problema aparecem 
como adequados ou inadequados, conforme um entendimento que nunca é absolutamente imutável. Devem ser entendidos de um modo funcional, como possibilidades de orientação e como fios condutores do pensamento”. (VIEHWEG, 1979, p. 38).

Doravante, o procedimento tópico traduz-se em uma reflexão em busca de material para pensar - leia-se premissas -, antecedendo a reflexão lógica. Pois, “[...] como tarefa, a inventio é primária e a conclusio secundária. A tópica mostra como se acham as premissas; a lógica recebe-as e as elabora” (p. 40). Dessa forma, contrapõe-se ao modo de pensar sistemático, formado por longas cadeias dedutivas. O modelo de sistema fechado é incapaz de abarcar o pensamento tópico, visto que a constante vinculação ao problema faz com que as possíveis formulações sistemático-dedutivas sejam de curto alcance, cuja extensão é bastante reduzida. Tal caráter assistemático torna o pensamento problemático avesso às vinculações.

Viehweg lutará contra o espírito científico formalista, que busca tornar científica a Jurisprudência, através da exclusão da tópica. Por mais que tenha sido combatido ao longo da modernidade, o pensamento tópico sempre esteve necessariamente relacionado com a Jurisprudência, pois a esta é impossível desvincular-se do problema, tanto em sua estrutura total, quanto em seus princípios, conceitos e postulados:

Olhando para trás, comprova-se como do sistema jurídico lógico, isto é, de um nexo de fundamentos intacto, não resta já quase nada [...] Onde quer que se olhe, encontra-se a tópica, e a categoria do sistema dedutivo aparece como algo bastante inadequado, quase como um impedimento para a visão. (VIEHWEG, 1979, p. 83). ${ }^{5}$

5 Tópica e jurisprudência. Os topoi existentes no Direito - tais como autonomia da vontade, interesse público, boa-fé, soberania, interesse, legitimidade, dentre outros possuem um sentido vago, aberto, destituído de rigor lógico, o que bem demonstra como tais tópicos adquirem alguma significação tão somente a partir dos problemas concretos existentes, como a relação entre sociedade e indivíduo, o conflito entre liberdade e igualdade, a proteção do indivíduo diante dos possíveis desmandos estatais e, acima de tudo, a questão nuclear posta à Jurisprudência ao longo de toda a história, à qual, de certa forma, se reduzem todas as demais questões: a noção de justiça. 
Quanto à hermenêutica, a tópica também gera consideráveis contribuições, ao valorizar a importância do problema, atribuindolhe um significado mais abrangente. A atividade interpretativa deve se desenvolver dentro do estilo tópico - afirmativa esta que adquire maior significado se analisada sob o prisma das constantes transformações temporais da ordem jurídica. Permite com isso a abertura de novas possibilidades de entendimento, sem violar as antigas, mantendo as fixações já realizadas, dando-lhes novo rumo através da aplicação de novos pontos de vista. Desta forma, a legitimação das premissas se opera através da aceitação do interlocutor, o que significa dizer que o ponto de vista aceito é tido geralmente como fixado, não discutido, e até evidente. Em razão disso, Viehweg qualifica as premissas, diante do respectivo problema, da seguinte maneira: relevantes ou irrelevantes; admissíveis ou inadmissíveis; prevendo inclusive graus intermediários, como defensáveis, ainda defensáveis, dificilmente defensáveis; indefensáveis. Diversamente da legitimação, a fundamentação de uma premissa, por ser eminentemente uma questão de lógica, requer a existência de um sistema dedutivo, no qual a premissa possa ser reconduzida, através de uma cadeia de proposições, à proposição nuclear, ou na terminologia de Vico, ao primum verum. Todavia, tal sistema não pode existir na tópica, devido à já mencionada vinculação ao problema, que limita consideravelmente tanto a redução como a dedução.

Em suma, o pensamento tópico permite, a partir dos próprios dados materiais de um problema jurídico, o desenvolvimento de argumentos adequados e persuasivos que auxiliem em sua solução, mesmo quando não exista o apoio de uma norma legal. Com a tópica, a norma e o sistema perdem a sua hegemonia, passando a constituir meros topoi, simples pontos de vista, cedendo lugar ao primado do problema, que passa a configurar o eixo central da atividade interpretativa.

\section{0 método concretista da "Constituição aberta” de Peter Häberle}

Um dos autores a quem a tópica mais influenciou foi Peter Häberle. Sua metodologia implicará na radicalização da orientação tópico- 
problemática no campo da teoria da Constituição. Partindo da perspectiva conceitual de Karl Popper, defenderá a adequação da hermenêutica constitucional à sociedade aberta, através da democratização da interpretação da Constituição. Segundo o autor, a teoria da interpretação constitucional tem concentrado seus esforços em dois pontos principais: a questão acerca das tarefas e objetivos da interpretação; e a questão acerca dos métodos, que envolve o processo da interpretação e suas regras. Todavia, há um aspecto fundamental para o qual não se tem dado a devida importância: a questão relativa aos participantes da interpretação. Isto se dá em razão do forte vínculo que a teoria da interpretação constitucional tem mantido com um modelo de sociedade fechada, conferindo especial destaque aos procedimentos formalizados e à interpretação constitucional realizada pelos magistrados. Contudo, por mais importante que seja a interpretação constitucional dos juízes, ela não é a única possível.

Mais precisamente, Häberle deseja operar uma síntese entre a Constituição e a realidade constitucional, destacando o papel fundamental exercido pelos agentes que conformam esta realidade. Doravante, busca analisar as implicações decorrentes de uma revisão da metodologia jurídica clássica - vinculada ao conceito de sociedade fechada - e trabalhar uma metodologia centrada no modelo aberto e pluralista de sociedade, tendo como eixo principal o problema dos participantes do processo de interpretação constitucional.

Destaca, assim, que a interpretação tem sido tradicionalmente considerada tão somente como uma atividade dirigida, de modo consciente e intencional, à compreensão e explicitação do sentido de um texto. Obviamente, esta concepção restrita - reflexo da metodologia civilista proposta por Savigny - é insuficiente à análise hermenêutica realista proposta por Häberle, tornando-se necessário o uso de um conceito mais amplo de interpretação, que reconheça a relevância do espaço público na sociedade aberta. Por isso, ele irá propor a tese de que não é possível o estabelecimento de um número limitado de intérpretes da Constituição, na medida que todos os órgãos estatais e potências públicas, assim como todos os grupos e cidadãos, estejam envolvidos nesse processo de interpretação, que deverá ser tão mais aberto quanto mais pluralista for uma sociedade. 
Tal afirmativa se fundamenta no fato de que todos aqueles que vivem a norma devem ser considerados como forças produtivas da interpretação, isto é, intérpretes lato sensu da Constituição, ou ao menos pré-intérpretes (Vorinterpreten): “Toda atualização da Constituição, por meio da atuação de qualquer indivíduo, constitui, ainda que parcialmente, uma interpretação constitucional antecipada” (HÄBERLE, 1997, p. 13-14). Contudo, isso não significa a supressão da responsabilidade da jurisdição constitucional, tampouco nega sua relevância no que diz respeito ao processo interpretativo. Trata-se apenas de reconhecer a influência da teoria democrática sobre a hermenêutica constitucional, conferindo-lhe maior legitimidade. Como os intérpretes jurídicos da Constituição não são os únicos que vivem a norma, não podem monopolizar a atividade interpretativa: “Todo aquele que vive no contexto regulado por uma norma e que vive com este contexto é, indireta ou até mesmo diretamente, um intérprete dessa norma. O destinatário da norma é participante ativo, muito mais ativo do que se pode supor tradicionalmente do processo hermenêutico" (HÄBERLE, 1997, p. 15). Logo, a interpretação constitucional só pode ser pensada tendo em vista a esfera pública e a realidade constitucional, de modo que não é mais possível desconsiderar o papel do cidadão e das demais potências públicas na interpretação da Lei Maior.

Em outras palavras, significa o abandono do modelo hermenêutico tradicional, construído a partir de uma sociedade fechada, reconhecendo que não apenas o processo de formação é pluralista, mas também todo o desenvolvimento posterior, de modo que a teoria da Constituição assim como a teoria da democracia - exercem um papel mediador entre Estado e sociedade. Tanto do ponto de vista teórico quanto do ponto de vista prático, a interpretação da Constituição não constitui um fenômeno absolutamente estatal, pois, além dos órgãos estatais e dos participantes diretos, todas as forças da comunidade política - ainda que de forma potencial - também têm acesso a esse processo. O papel exercido pelas pessoas concretas merece destaque na teoria de Häberle, inclusive no que diz respeito às funções estatais - leia-se parlamentares, funcionários públicos e juízes. A isto ele denomina personalização da interpretação constitucional. 
No que tange ao processo político, Häberle reconhece sua relevância para a interpretação da Constituição. O legislador também possui um poder de conformação, assim como o juiz constitucional. A diferença existente se situa no plano qualitativo, ou seja, ao juiz é assegurado um espaço na interpretação cujos limites decorrem de argumentos de índole técnica. Todavia, sob o prisma quantitativo, não existiria, segundo o autor, diferença fundamental entre as duas situações. Vale a transcrição de suas palavras:

O muitas vezes referido processo político, que, quase sempre, é apresentado como uma subespécie de processo livre em face da interpretação constitucional, representa, constitucione lata e de fato, um elemento importante - mais importante do que se supõe geralmente - da interpretação constitucional, (política como interpretação constitucional). Esse processo político não é eliminado da Constituição, configurando antes um elemento vital ou central no mais puro sentido da palavra: ele deve ser comparado a um motor que impulsiona esse processo. Aqui, verificam-se o movimento, a inovação, a mudança, que também contribuem para o fortalecimento e para a formação do material da interpretação constitucional a ser desenvolvida posteriormente. Esses impulsos são, portanto, parte da interpretação constitucional, porque, no seu quadro, são criadas realidades públicas e, muitas vezes, essa própria realidade é alterada sem que a mudança seja perceptível. (HÄBERLE, 1997, p. 26).

Observa-se que parte da esfera pública (Öffentlichkeit), assim como da realidade constitucional, é criada pelo legislador, de modo que seu papel possui uma função precursora na interpretação da Lei Maior e no processo de mutação constitucional, influenciando inclusive o posterior desenvolvimento dos princípios constitucionais. Por fim, a interpretação da Constituição também é influenciada pela Ciência do Direito Constitucional, catalisada principalmente por intermédio da jurisdição constitucional.

Häberle continua sua exposição, buscando demonstrar a legitimação das forças participantes do processo interpretativo. Primeiramente, ele 
reconhece as possíveis críticas em relação ao seu trabalho. A principal delas traduz-se na constatação de que uma teoria constitucional defensora do postulado da unidade da Constituição, assim como da produção de uma unidade política, deve reconhecer o risco de a interpretação constitucional (dependendo de como for praticada) acabar se dissolvendo em um número excessivamente elevado de intérpretes e de interpretações, o que levaria à redução do elemento normativo, ou até à sua anulação.

Os defensores dessa crítica alegam que a legitimação para a interpretação deveria ocorrer de modo restrito, tão somente ao nível dos entes nomeados pela Constituição para realizar sua interpretação. Entretanto, Häberle entende que esse argumento perde sua força a partir do momento em que consideramos um novo fator a orientar a hermenêutica constitucional: o reconhecimento de que a interpretação é um processo aberto, onde a ampliação do círculo de intérpretes decorre da necessidade de integrar a realidade no processo interpretativo.

A hermenêutica não se confunde, então, com um processo de passiva submissão, com a mera recepção de uma ordem, pois interpretar uma norma significa colocá-la no tempo, integrá-la à realidade pública. Logo, a regra jurídica não é uma decisão prévia, simples e acabada; pelo contrário, é dependente da atividade exercida por todos os participantes de seu desenvolvimento funcional - que configuram forças ativas de sua interpretação, partes da publicidade e da realidade constitucional. Isto implica não apenas na personalização, mas também na pluralização da interpretação constitucional. Da mesma forma, não tem fundamento a alegação de que a ampliação do círculo de intérpretes ameaçaria a independência dos juízes e a vinculação à lei. Isto porque não é possível, através de tais fatores, tentar ocultar o fato de que o juiz interpreta a Constituição na esfera pública e em face da realidade. O intérprete sempre se orienta pela teoria e pela práxis. Esta última, no entanto, não é conformada pura e simplesmente pelos intérpretes oficiais da Constituição:

Uma Constituição que estrutura não apenas o Estado em sentido estrito, mas também a própria esfera pública, dispondo sobre a organização da própria sociedade e, diretamente, sobre setores da vida privada, não pode tratar as forças sociais e privadas 
como meros objetos. Ela deve integrá-las ativamente enquanto sujeitos [...]. Limitar a hermenêutica constitucional aos intérpretes 'corporativos' ou autorizados jurídica ou funcionalmente pelo Estado significaria um empobrecimento ou um autoengodo”. (HÄBERLE, 1997, p. 33-34).

A abordagem proposta por Häberle traz consequências para o próprio processo constitucional: "Colocado no tempo, o processo de interpretação constitucional é infinito, o constitucionalista é apenas um mediador (Zwischenträger)” (HÄBERLE, 1997, p. 42). Acrescente o fato de que diversos problemas em torno da Constituição material não chegam à Corte Constitucional e será possível perceber que, mesmo sem a interpretação judicial, a Constituição subsiste. Em uma sociedade aberta, existem outras vias que levam à interpretação da Lei Maior, o processo constitucional formal não é a única. Torna-se, pois, necessário o aperfeiçoamento dos instrumentos de informação dos juízes, principalmente quanto ao alargamento da possibilidade de participação no processo constitucional, permitindo, por conseguinte, uma comunicação efetiva entre os diversos atores desse amplo processo de interpretação. Em outras palavras, o processo constitucional passa a ser parte do direito de participação democrática. ${ }^{6}$

6 Em texto mais recente, Häberle situa a teoria da Constituição enquanto parte de uma realidade cultural, vendo na cultura - entendida a partir de seus três aspectos essenciais: tradição, inovação e pluralismo - o contexto orientador de todo o Direito, assim como de sua práxis. Direito e Cultura estariam, pois, intimamente relacionados, o que é perceptível não apenas no âmbito material de determinadas normas constitucionais (como, por exemplo, as relativas à educação, à arte, à ciência, etc.), mas também nas formas técnico-jurídicas pelas quais se manifestam (englobando aspectos jurídicos individuais, institucionais e também corporativos). Nota-se aqui que o direito constitucional cultural proposto por Häberle assenta-se nos mesmos princípios de sua obra anterior, pressupondo o entendimento da cultura enquanto uma realidade aberta, capaz de dar conta do pluralismo hoje existente. A Constituição não se limita para Häberle a uma mera reunião de normas, tampouco é determinada unicamente por fatores materiais, sejam estes entendidos como a estrutura econômica de Marx, ou os fatores reais do poder de Lassalle. Ela constitui, fundamentalmente, a expressão do legado cultural de determinado povo, de sua tradição e de sua experiência histórica, assim como o reflexo de suas esperanças, de suas expectativas e possibilidades reais de configuração futura, de modo que a Constituição sempre se encontra em uma relação de dependência cultural em relação a todo o povo, constituindo 


\section{Conclusões}

Expusemos no item anterior parte do estudo interdisciplinar desenvolvido por Peter Häberle, no qual o autor destaca o relacionamento íntimo existente entre Estado e sociedade, espaço público e interesse público, assim como suas respectivas implicações no que tange à hermenêutica constitucional (TORRES, 1995). Cabe agora analisar os limites e possibilidades de sua aplicação à realidade constitucional brasileira.

A abertura do círculo de intérpretes da Constituição, na medida em que fundamenta e legitima a atividade do Judiciário diante do fato do pluralismo, constitui uma preocupação de qualquer Estado de Direito que se pretenda democrático e social. Sob uma perspectiva mais geral, não se trata de outra coisa senão reconhecer a mútua implicação existente entre fato e norma constitucional, de modo que a integração da realidade no processo de interpretação constitucional fortaleça a unidade política, compatibilizando o ordenamento jurídico ao modelo de sociedade aberta e pluralista.

ao mesmo tempo um ser e um dever-ser. Seu resultado é, pois, obra de todos os intérpretes de uma sociedade que é aberta e pluralista. Desse modo, a tarefa da exegese constitucional não está restrita ao momento da interpretação dos textos normativos, ganhando relevância o papel condicionador que os requisitos culturais exercem sobre a pré-compreensão do intérprete, a ponto de até mera explicitação do teor literal de uma norma ser determinada pelo respectivo contexto cultural. Consequentemente, toda modificação cultural termina por implicar em uma transformação da própria exegese, configurando à cultura o pano de fundo material no qual se move a hermenêutica constitucional. Häberle promove, assim, uma relativização do conteúdo dos textos normativos: "El aserto de $R$. Smend, de 1951, de que 'cuando dos leyes fundamentales dicen lo mismo, ello no significa que sea lo mismo'nos lleva a cuestionar cómo es posible justificar el hecho de que los mismos textos jurídicos que aparecen tanto en los llamados 'pactos sobre derechos humanos' entre el Este y el Oeste, como en las respectivas Constituciones occidentales, puedan y de hecho deban ser interpretados en el tiempo y en el espacio de formas diferentes. El telón de fondo material que vincula a cada uno de los diferentes criterios hermenéuticos no es otro que las proprias culturas nacionales que subyacen a cada una de tales Constituciones; dicho com otras palabras: que el mismo texto encierra diferente contenido en cada una de las culturas en las que aparece, y todo ello además en función tanto del tiempo como del espacio" (HÄBERLE, 2000, p. 45). 
Por certo, a despeito das contribuições da teoria de Häberle, a busca de atualização da Constituição diante dos aos valores pluralistas, caso não seja feita mediante ressalvas que racionalizem o processo de participação dos novos protagonistas da atividade interpretativa constitucional, terminará por implicar, em última instância, na submissão da Carta política aos fatores reais de poder. ${ }^{7}$ Daí que o desenvolvimento de suas teses dependa necessariamente do aprimoramento das instituições democráticas e dos procedimentos deliberativos, de modo a torná-los condizentes com o modelo de sociedade aberta que deve balizar a estruturação de todo e qualquer Estado que se pretenda constitucional. ${ }^{8}$

7 De fato, não apenas as proposições de Häberle, mas inclusive a força normativa da Constituição de Hesse, demonstra um forte vínculo com o realismo jurídico de Lassalle, na medida em que buscam constitucionalizar os fatores reais do poder. Ocorre apenas que Lassalle desenvolve um sociologismo preso ao contexto de uma sociedade fechada, razão pela qual não logrou desvendar alternativas institucionais para os conflitos entre a Constituição jurídica e a Constituição real, enquanto que Häberle, ao desenvolver seu pensamento a partir da noção de sociedade aberta, possibilitou um aporte dialético entre fatos e normas.

8 O estado constitucional é entendido por Häberle como criação jurídica do poder público, poder este limitado por princípios constitucionais formais e materiais, garantidores dos requisitos necessários à existência do regime democrático. Em última instância, a democracia encontrar-se-ia associada ao pluralismo e aos demais atributos característicos da sociedade aberta, assim enunciados pelo jurista alemão: “[...] la dignidad humana como premisa, realizada a partir de la cultura de un pueblo y de los derechos universales de la humanidad, vividos desde la individualidad de ese pueblo, que encuentra su identidad en tradiciones y experiencias historicas, y sus esperanças en los deseos y la voluntad creadora hacia el futuro; el principio de la soberanía popular, pero no entendida como competencia para la arbitrariedad ni como magnitud mística por encima de los ciudadanos, sino fórmula que caracteriza la unión renovada constantemente en la voluntad y en la responsabilidad pública; la Constitución como contrato, en cuyo marco son posibles y necesarios fines educativos y valores orientadores; el principio de la división de los poderes tanto en sentido estricto, relativo al Estado, como en el sentido amplio del pluralismo; los principios del Estado de derecho y el Estado social; las garantías de los derechos fundamentales; la independencia de la jurisdicción [...] Todo esto se incorpora en una democracia ciudadana constituida por el principio del pluralismo [grifos nossos]” (HÄBERLE, 2001, p. 1-2; 2007, p. 6-7). Ressalte-se, contudo, que não se trata de um rol exaustivo, mas de um conjunto de elementos ideais e reais, resultantes, em parte, do estudo constitucional comparado e que, apesar de raramente se verificarem em sua plenitude nos Estados, são indicadores de uma situação ótima do que deve ser, sustentada no que efetivamente é, nos moldes do pensamento possibilista 


\section{Referências}

BARROSO, Luís Roberto. Interpretação e aplicação da constituição. 3. ed. São Paulo: Saraiva, 1999.

BOBBIO, Norberto. O positivismo jurídico: lições de filosofia do direito. Tradução de Márcio Pugliesi, Edson Bini, Carlos E. Rodrigues. São Paulo: Ícone, 1999.

BOBBIO, Norberto. Teoria do ordenamento jurídico. 7. ed. Tradução de Maria Celeste C.J. Santos. Brasília: UnB, 1996.

BÖCKENFÖRDE, Ernst-Wolfgang. Los métodos de la interpretación constitucional - inventario y crítica. In: Escritos sobre derechos fundamentales. Tradução de Ignacio Villaverde Menéndez. Baden-Baden: Nomos, 1993.

BÖCKENFÖRDE, Ernst-Wolfgang. Curso de direito constitucional. 10. ed. São Paulo: Malheiros, 2000.

BONAVIDES, Paulo. Apresentação. In: Métodos de trabalho do direito constitucional. Tradução de Peter Naumann. Porto Alegre: Síntese, 1999.

CAMARGO, Margarida Maria Lacombe. Hermenêutica e argumentação: uma contribuição ao estudo do direito. Rio de Janeiro: Renovar, 1999.

CANOTILHO, J. J. Gomes. Direito constitucional e teoria da constituição. 3. ed. Coimbra: Almedina, 1999.

COELHO, Inocêncio Mártires. Elementos de teoria da constituição e de interpretação constitucional. In: BRANCO, Paulo Gustavo Gonet; COELHO, Inocêncio Mártires; MENDES, Gilmar Ferreira. Hermenêutica constitucional e direitos fundamentais. Brasília: Brasília Jurídica, 2000.

MENDES, Gilmar Ferreira. As idéias de Peter Häberle e a abertura da interpretação constitucional no direito brasileiro, 1998. Disponível em: $<$ http://www.idp.org.br/ideias.htm>. Acesso em: 12 dez. 2000.

fundado no trinômio realidade, necessidades, possibilidades. Não se trata, portanto, de alguma espécie de otimismo infundado, tal como acusam seus críticos. 
MENDES, Gilmar Ferreira. Interpretação constitucional. Porto Alegre: safE, 1997.

MENDES, Gilmar Ferreira. Konrad Hesse e Peter Häberle: um retorno aos fatores reais de poder. Disponível em: <http://www.idp.org.br/konrad. htm>. Acesso em: 05 jun. 2000.

FERRAZ JR., Tércio Sampaio. Introdução ao estudo do direito: técnica, decisão, dominação. 3. impr. São Paulo: Atlas, 1991.

FERRAZ JR., Tércio Sampaio. Prefácio do tradutor. In: VIEHWEG, Theodor. Tópica e jurisprudência. Brasília: Departamento de Imprensa Nacional, 1979.

GRAU, Eros Roberto. O direito posto e o direito pressuposto. 3. ed. São Paulo: Malheiros, 2000.

HÄBERLE, Peter. El estado constitucional. Tradução de Héctor FixFierro. México: Universidad Nacional Autónoma de México, 2001. HÄBERLE, Peter. O estado constitucional cooperativo. Tradução de Marcos Maliska e Elisete Antoniuk. Rio de Janeiro: Renovar, 2007. HÄBERLE, Peter. Hermenêutica constitucional - a sociedade aberta dos intérpretes da constituição: contribuição para a interpretação pluralista e procedimental da constituição. Tradução de Gilmar Ferreira Mendes. Porto Alegre: safE, 1997.

HÄBERLE, Peter. Teoría de la constitución como ciencia de la cultura. Tradução de Emilio Mikunda. Madrid: Technos, 2000.

HESSE, Konrad. Elementos de direito constitucional da República Federal da Alemanha. Tradução de Luís Afonso Heck. Porto Alegre: safE, 1998.

KELSEN, Hans. Teoria pura do direito. Tradução de João Baptista Machado. 6. ed. 4. tiragem. São Paulo: Martins Fontes, 2000.

LARENZ, Karl. Metodologia da ciência do direito. Tradução de José Lamego. 3. ed. Lisboa: Calouste Gulbenkian, 1997.

LASSALLE, Ferdinand. A essência da constituição. 4. ed. Rio de Janeiro: Lumen Juris, 1998. 
MAIA, Antônio Cavalcanti. Notas sobre direito, argumentação e democracia. In: CAMARGO, Maria Lacombe (Org.). 1988 -1998: uma década de constituição. Rio de Janeiro: Renovar, 1999.

MÜLLER, Friedrich. Métodos de trabalho do direito constitucional. Tradução de Peter Naumann. Porto Alegre: Síntese, 1999.

PERELMAN, Chaïm. Lógica jurídica: nova retórica. 2. impr. São Paulo: Martins Fontes, 1999.

PERELMAN, Chaïm. A teoria pura do direito e a argumentação. Tradução de Ricardo R. Almeida, 1993. Disponível em: <http://www.rdc. puc-rio.br/depto/direito/pet_jurídico/ clperelm.htm>. Acesso em: 05 jun. 2000.

SCHIER, Paulo Ricardo. Filtragem constitucional: construindo uma nova dogmática jurídica. Porto Alegre: safE, 1999.

SILVA, Kelly Susane Alflen da. Hermenêutica jurídica e concretização judicial. Porto Alegre: safE, 2000.

SMEND, Rudolf. Constitución y derecho constitucional. Madrid: Centro de Estudios Consitucionales, 1985.

TORRES, Ricardo Lobo. O espaço público e os intérpretes da constituição. Direito, estado e sociedade, Revista do Departamento de Direito da PUC-Rio. n.7, jul./dez. 1995.

VIEHWEG, Theodor. Tópica y filosofia del derecho. Tradução de Jorge M. Seña. Barcelona: Gedisa, 1991.

VIEHWEG, Theodor. Tópica e jurisprudência. Tradução de Tércio Sampaio Ferraz Júnior. Brasília: Departamento de Imprensa Nacional, 1979. 